Article

\title{
What Determines Lean Manufacturing Implementation? A CB-SEM Model
}

\author{
Tan Ching $\mathrm{Ng}^{1, *}$ and Morteza Ghobakhloo ${ }^{2}$ \\ 1 Department of Mechanical and Material Engineering, Universiti Tunku Abdul Rahman, \\ Kajang 43000, Malaysia \\ 2 Department of Industrial Engineering, Minab Higher Educational Center, University of Hormazgan, \\ Hormozgan 3995, Iran; morteza_ghobakhloo@yahoo.com \\ * Correspondence: ngtc@utar.edu.my; Tel.: +60-012-603-1830
}

Received: 18 May 2017; Accepted: 18 December 2017; Published: 5 February 2018

\begin{abstract}
This research aims to ascertain the determinants of effective Lean Manufacturing (LM). In this research, Covariance-based Structural Equation Modeling (CB-SEM) analysis will be used in order to analyze the determinants. Through CB-SEM analysis, the significant key determinants can be determined and the direct relationships among determinants can be analyzed. Thus, the findings of this research can act as guidelines for achievement of LM effectiveness, not only providing necessary steps for successful implementation of lean, but also helping lean companies to achieve higher level of lean cost and time savings.
\end{abstract}

Keywords: lean manufacturing; key determinants; Covariance-based structural equation modeling (CB-SEM)

\section{JEL Classification: L60}

\section{Introduction}

Over the last few decades, Lean Manufacturing (LM) has become a trend around the world for many manufacturing companies in various industries. Until today, the core benefits of LM (flow, minimizing wastes, etc.) have become the paradigm for many manufacturing operations (Womack and Jones 2010).

LM is one of the most well-known systems that could possibly results in productivity improvement. Lean tools that commonly apply in a company include Kaizen, Kanban, Just In Time (JIT), Supply Chain Management (SCM), Total Quality Management (TQM), Total Productive Maintenance (TPM), the seven waste concept (MUDA), and the 5S workplace methodology (Herron and Braiden 2006). By implementing LM, the overall productivity can be increased by increasing the output product and decreasing the input factors such as processing lead time, transportation time, man power, raw materials and defect products. With the aid of LM, the company can increase their profit margin through the improvements gained. According to Lapinski et al. (2006), LM constantly adjusts the manufacturing process to achieve savings and quality improvements.

There are many studies about the successfulness of LM implementation. However, there have been doubts raised against the effectiveness of LM. Loughrin (2010) asked whether LM was the main reason that causing the recalling of certain Toyota models, as LM is more focused on productivity rather than the quality of the product produced. Additionally, LM performance also raises a number of theoretical and methodological concerns (Womack and Jones 2010). Even for those who have applied LM, they are still considering it as an uncertainty in terms of its effectiveness after years of implementation (Deif 2012). Fliedner and Majeske (2010) has discussed how to make LM longer, but still without a clear statement of how long LM needs to be for achieving effectiveness. 
In Malaysia, LM is very famous even among small and medium enterprise. Today, not only Malaysian, but other developing countries' manufacturing companies are also aware of the effective level of LM systems that are already implemented. Nevertheless, there is limited study or research on the long-lasting effectiveness of LM. The analysis of LM effectiveness level is not only benefit to the current manufacturing industries, but also affects the future development of LM. Hence, there is a necessity to figure out the effective level of lean systems in those manufacturing companies, to ensure the benefits obtained from the lean tools implemented are long lasting (Jamian et al. 2012). There is still lack of research, both statistical and anecdotal, about which lean tools are essential and critical when it comes to the LM effectiveness, especially in Malaysia. Proper and proven guidelines could have assisted the current and future lean manufacturers in Malaysia to achieve high efficiency lean outcomes with least resources involved, which means reducing unnecessary waste (Shetty et al. 2010); unfortunately, such guidelines are lacking. In addition, Wong and Wong (2011) and Nordin et al. (2010) mentioned that there is an urgent need to examine the relationship between LM practices due to there being a lack of needed information regarding LM effectiveness in the overall manufacturing sector in Malaysia.

\section{Problem Statement}

LM is famous among the industry as it can go well beyond cost-cutting while bringing benefits to the organizations at the same time. Poduval and Pramod (2015) claimed that LM can help in enhancing an organization's productivity, producing high quality goods and minimizing wastes and thereby reducing costs (Poduval and Pramod 2015). In addition, well-implemented LM enables them to have a rapid response towards customer request, which can deliver considerable benefits to the organizations (Melton 2004).

Holweg (2007) mentioned that LM is a huge management topic that consists of a collective of lean tools to solve different problems encountered by different industries. There is an adequate number of studies or researches providing evidence regarding the advantages of LM implementation. For instance, LM is commonly known as an efficient tool in order to enhance the shop floor productivity by eliminating the seven common wastes (Fliedner and Majeske 2010). Even the ways that Toyota company implement and utilize the well-known lean system are clearly described by Dawson ((1994). However, there are still doubts about the effectiveness of lean system. Some of the companies are not sure about the further contribution (other than productivity) of LM system after implementing it. The information gathered shows that even a small furniture production company that has integrated lean tools is still keen on finding the ways to preserve valuable resources in maintaining their productivity system (Miller et al. 2010). Another example is the Toyota Company, which also suffered from slumping sales and is keen on finding the ways to improve the lean implementation system, which seems to be one of the main reasons (Wartzman 2007). As time goes by, the environment, the manufacturing process and product, the human factors, or even the customers' requirements may be varied from what they were several years ago.

Nevertheless, the lean effectiveness level in Malaysia has yet to be investigated. There is still lack of researches studying LM effectiveness after years of implementation, which has led to the commencement of this research (Nordin et al. 2010; Wong and Wong 2011). In the long term global perspective, an effective strategy is the best, and perhaps the only opportunity to achieve a greater level of LM.

Since the awareness of long term effectiveness is now the worldwide concern for many organizations (United Nations Environment Programme, Division of Early Warning, and Assessment 2011); therefore, the requirement of knowing lean effectiveness in Malaysia is getting higher among the implementers. With the cost of lean system implementation being high, manufacturers are curious if the system could be able to maintain satisfying results in productivity, or the system or can only last for a short period of time. Hence, this study is concerned with the competitive impact of lean production. The measure and analysis of the lean effectiveness level in Malaysia's manufacturing organizations are 
obviously vital to the manufacturers and researchers. Thus, the local lean trends such as key determinants of lean, lean tools most adopted by Malaysia's manufacturers and the effectiveness of LM will be investigated within this study.

From the above, the existing problems in the research context of this study can be summarized as follow:

1. Lack of understanding of the impact of LM implementation on business performance;

2. Lack of knowledge of the key determinants of LM implementation;

3. Lack of knowledge of the interrelationship among key determinates of LM that can affect LM effectiveness.

4. Lack of successful statistically proven lean models based on Malaysia's existing LM trend that can be used as a reference for existing and future lean organizations towards a successful lean outcome.

\section{Literature Review}

The term "lean manufacturing" is an approach practiced to eliminate waste in a production that consumes resources, but creates no value to customers (Anvari et al. 2011). LM, also known as lean thinking, is a comprehensive set of technique that maximizes customer value, allowing customers to obtain the best quality products. It is well-known for eliminating wastes and non-value-added activities by using the least resources (Karim and Arif-Uz-Zaman 2013). Through LM, the percentage of wastes on excessive resources can be reduced or eliminated, same to the defects products and non-value-added activities. However, the effectiveness of LM is closely related to how far the lean is implemented. For instance, implementation of more than one lean tool generally has higher effectiveness compared to one lean tool implementation (Anand and Kodali 2009; Kumar et al. 2013; Karim and Arif-Uz-Zaman 2013; Hibadullah et al. 2014).

LM systems emphasize reducing processing time, reducing non-value-added activity and eliminating waste in order to increase productivity in terms of quality and quantity. The concepts of the lean tools are ultimately useful in the shop floor practices and also in the service industries. For example, the Kaizen principle is mainly for continuous improvement to the system no matter how small it is. It contributes in discovering and removing waste in the manufacturing processes whenever there is an opportunity. It is the base for long term success of LM. Other than that, lean tools that involved continuous improvement elements include JIT, TQM, TPM, SCM, 5S, Kanban and so on (Shah and Ward 2003, 2007; Sharma and Shudhanshu 2012; Taylor and Wright 2003). JIT is a technique used to monitor the inventory level of a production and control the amount of materials used in each workstation to prevent overproduction (Feld 2001). The main concept of JIT is to produce the products in a single time in order to meet the demand. TQM, as described in Besterfield et al. (1995), is a helpful philosophy with a complete set of guiding steps and principles that plays an important role in the continuous improvement routine in organizations. TPM does not only perform random check up on machines, it also functions as planning for maintenance service regularly on all equipment and this task is usually distributed for workers for detecting abnormalities, failures or errors when they occur (Feld 2001). The goal of TPM is to improve the productivity and quality of the manufacturing operations along with increased employee morale and job satisfaction (Singh et al. 2013). In addition, SCM is a life circulation procedure supporting financial, knowledge, physical, and information flows for shifting services and products from suppliers to customers (Ayers 2002). With lean systems, the production is able to immediately change and fulfill market demands (Murman et al. 2002).

However, there are some reviews debating and questioning the effectiveness of LM systems. Kilpatrick (2003) stated that, in some companies, LM application takes a long duration before changes and improvement can be observed. LM may end up in the successor of that organization and continue without any outcome achieved. Kilpatrick (2003) also brought up the question of how long does LM take to have an effect, and what should lean executers do to achieve an effective lean outcome. Generally, failure of lean implementation is due to lack of understanding towards LM. This philosophy 
has to be accepted in the higher-level management before instructing the lower-level employees and officers to follow the application (Kilpatrick 2003; Nordin et al. 2010; Byfuglien et al. 2013).

Although lean can be made clear and fully understood, there are possibilities that LM may plan in the wrong sequence and causes negative effect to the organization. Also, Nordin et al. (2010) stated that the lack of communication and training, different culture and employee's behaviour can cause unsuccessful implementation of lean. Meanwhile, Byfuglien et al. (2013) mentioned that LM can be a new knowledge to employees before its implementation. It requires the willingness to change and openness of employees. Besides, proper improvement evaluation and follow up are needed at all times to ensure the targets towards the continuous improvement are achieved (Byfuglien et al. 2013). With a significant number of researchers in the world giving different opinions in the key determinants that could affect effective lean outcomes, it is critical for this study to identify the key determinants to achieve the highest lean effectiveness outcome in the Malaysian manufacturing industry.

\section{Research Methodology}

\subsection{The Sampling Frame}

The sampling frame of this study consists of all manufacturing firms located in Peninsular Malaysia. The data were collected by means of a survey administered in different manufacturing companies and through a multiple informant technique. A sample of 250 sets of questionnaires of potentially qualified Malaysian manufactures was identified from various sources and through assistances of Federation of Malaysian Manufacturers and organizations from Malaysia Ministry of Industry and International Trade. Finally, and after conducting follow up activities, 165 valid questionnaires were received for a response rate of $66 \%$.

Non-response bias was assessed by comparing early respondents with late respondents. The rationale for this test is that late respondents are likely to have similar characteristics to non-respondents. To compare early with late responses, we defined the first $25 \%$ of the received questionnaires as early responses and the last $25 \%$ were regarded as late responses. The t-test results revealed no significant difference on sample characteristics in the two groups.

\subsection{Instrument Development}

We primarily tried to develop the measurement items by adapting from validated existing scales from prior literature. We further followed existing guidelines and exemplars in the literature for developing new measures. After developing the initial survey instrument, we formed a focus group and a pretest was conducted through interviews with a focus group. Based on the pretest, the few additional items that were not captured through the literature review were added, and items that were not clear, not representative of the domain, or that were severely open to misinterpretation were finally eliminated. Following this stage, two well-established scholars having substantial experience in survey research and expertise in the subject domain were asked to assess the instrument. Next, and after applying improvements suggested from these scholars, and to test and assure face validity of the questionnaire, we piloted the questionnaire among 20 manufacturing units. Based on the feedback from the pilot study, some questions were rephrased to improve their clarity. As a result, some minor revisions were applied to the questionnaire before final data collection.

\section{Data Analysis}

The Covariance-based Structural Equation Modeling (CB-SEM) was used to analyze the data and the proposed relationships (Hair et al. 2006). In doing so, we followed Anderson and Gerbing (1988) recommended two-step approach to test our hypotheses. At the first step, the measurement model was tested to establish validity and reliability of the scales used in our analysis. And at the second step the test of structural relationships was performed. As compared to other SEM techniques such as Partial Least Squares Structural Equation Modeling (PLS-SEM), CB-SEM is more suitable for our 
study because the justification for the specification of the dependence relationships in our model is entirely theory-driven, and CB-SEM is most suited when the objective is to test or extend a profoundly theory-driven path model (Hair et al. 2006, 2013). Therefore, we used IBM AMOS (v. 20.0.0, 2011, New York, NY, USA) to perform the desired CB-SEM analysis in this study.

\subsection{Measurement Model}

We first assessed the overall fit of the first-order measurement model. Following Hair et al. (2006) and Hu and Bentler (1998) recommendations, we controlled for multiple goodness-of-fit indices namely Chi-square (CMIN or $\chi 2$ ) statistic/DF, Root Mean Square Error of Approximation (RMSEA), Root Mean Square Residuals (RMR), and standardized RMR (SRMR), Comparative Fit Index (CFI), Goodness-of-Fit Index (GFI), Incremental Fit Index (IFI), Normed Fit Index (NFI), Relative Fit Index (RFI), and Tucker-Lewis Index (TLI). Since RMSEA = 0.029, CMIN $/ \mathrm{DF}=1.286, \mathrm{RMR}=0.024, \mathrm{SRMR}=0.042, \mathrm{CFI}=0.980, \mathrm{IFI}=0.971$, $\mathrm{TLI}=0.964, \mathrm{GFI}=0.926, \mathrm{NFI}=0.920$ and $\mathrm{RFI}=0.917$, we concluded that the measurement model had a good fit with the data (Hair et al. 2006; Hu and Bentler 1998).

The measurement model validity was further evaluated using four validity measures: content validity, internal consistency, convergent validity and discriminant validity (Petter et al. 2007). The content validity was ensured as (i) we employed measurement items adapted from existing and validated scales; (ii) we acted based on a standard procedure previously established in the literature for new and significantly changed measurements (e.g., pretest); and (iii) we refined the measurement instrument with two well-established scholars and performed the pilot study on 20 manufacturing units.

The result of confirmatory factor analysis, and the measurement properties of items and their internal consistency reliabilities are listed in Table 1. This table suggested that all the factor leadings were 0.6 or higher, which were above the threshold of 0.5 suggested by Hair et al. (2006). Moreover, all the Cronbach's alpha and composite reliability values for existing measures were 0.7 or higher, well above the recommended level of 0.70 , indicating adequate internal consistency (Fornell 1982). Fornell and Larcker (1981) suggested that convergent validity is adequate when constructs have an Average Variance Extracted (AVE) of at least 0.5. This provided further evidence of convergent validity as AVE or all variables were significantly higher than 0.5 in this study (Table 1). 
Table 1. Measurement properties of constructs.

\begin{tabular}{|c|c|c|c|c|c|c|}
\hline First-Order Constructs & Number of Items & Coding & Factor Loadings & Cronbach's Alpha & Composite Reliability & Average Variance Extracted \\
\hline Employees' empowerment & 4 & $\mathrm{EE}$ & $0.793-0.854$ & 0.849 & 0.876 & 0.582 \\
\hline Employees' involvement & 5 & EI & $0.723-0.848$ & 0.886 & 0.901 & 0.653 \\
\hline Implementation costs & 4 & IC & $0.770-0.856$ & 0.879 & 0.908 & 0.691 \\
\hline Teamwork & 6 & TW & $0.711-0.874$ & 0.908 & 0.921 & 0.702 \\
\hline Managerial leadership and support & 5 & MLS & $0.760-0.859$ & 0.904 & 0.917 & 0.681 \\
\hline Awareness of latest lean information & 5 & ALI & $0.723-0.799$ & 0.820 & 0.832 & 0.594 \\
\hline IT investments & 1 & ITI & - & - & - & - \\
\hline Lean manufaturing & 4 & LM & $0.711-0.903$ & 0.841 & 0.863 & 0.647 \\
\hline Business performance & 3 & $\mathrm{BP}$ & $0.794-0.855$ & 0.731 & 0.814 & 0.645 \\
\hline
\end{tabular}


Although few variable inter-correlations were relatively high, the items demonstrated satisfactory discriminant validity as well. For satisfactory discriminant validity, the AVE from the construct should be greater than the variance shared between the construct and other constructs in the model (Chin 1998). This means that a construct is considered to be distinct from other constructs if the square root of the AVE for it is greater than its correlations with other latent constructs (Barclay et al. 1995). As in all cases, the square root of AVE for each construct was larger than the correlation of that construct with all other constructs in the model (Table 2 lists the correlation matrix, with correlations among constructs and the square root of AVE on the diagonal). The results satisfied the discriminant validity.

Table 2. Correlation matrix.

\begin{tabular}{cccccccccc}
\hline Coding & EE & EI & IC & TW & MLS & ALI & ITI & LM & BP \\
\hline EE & 0.763 & & & & & & & & \\
EI & 0.464 & 0.808 & & & & & & & \\
IC & -0.129 & -0.293 & 0.831 & & & & & & \\
TW & 0.375 & 0.496 & -0.314 & 0.838 & & & & & \\
MLS & 0.243 & 0.444 & -0.249 & 0.363 & 0.825 & & & & \\
ALI & 0.303 & 0.492 & -0.409 & 0.486 & 0.302 & 0.771 & & \\
ITI & 0.305 & 0.243 & 0.278 & 0.318 & 0.402 & 0.426 & 1.000 & & \\
LM & 0.208 & 0.129 & -0.218 & 0.298 & 0.196 & 0.261 & 0.211 & 0.804 & \\
BP & 0.117 & 0.206 & -0.043 & 0.276 & 0.142 & 0.077 & 0.158 & 0.742 & 0.803 \\
\hline
\end{tabular}

Note: The italic items on the diagonal represent the square roots of the Average Variance Extracted (AVE); The values of 1.00 on diagonal are indicative of correlations between the similar items which have no AVE.

The correlations matrix did not indicate any exceptionally correlated variables since the highest correlation among principal constructs was $r=0.742$. Evidence of common method bias usually results in very high correlations $(r>0.90)$ (Sai Hong and Ghobakhloo 2013). Finally, the test of multicollinearity aimed at identification of all potential collinearity problems (having more than one predictor construct) revealed that the variance inaction factor values for all the variables did not exceed the threshold generally accepted in the literature with values of 3.3 (e.g., Petter et al. 2007). As a result, these findings strongly supported the study's content validity, convergent validity, and discriminant validity of the operational measures and response scales.

\subsection{Structural Model}

The test of the structural model includes estimates of the path coefficients, which indicate the strengths of the relationships between the dependent and independent variables, and the $\mathrm{R}^{2}$ values, which represent the amount of variance explained by the independent variables (Rai et al. 2006). Together, the $\mathrm{R}^{2}$ and the path coefficients (loadings and significance) indicate how well the data support the hypothesized model. Figure 1 explains the results of the test of the hypothesized structural model. Table 3 represents the results of assessment of structural path model. This table indicates that all the direct relationships among determinates of LM is statistically significant at $p=0.05$. As expected, the majority of influencing factors, excluding IT and EI, have a significant positive effect on the implementation of LM. This result does not indicate the lack of importance of IT and EI in the development of LM. In fact, IT and EI have a significant positive effect on development of TW. Alternatively, TW is the most important determinant of LM implementation $(\beta=0.284, p=0.004)$. Hence, the effects of IT and EI are indeed indirect and through the mediating role of TW. Additionally, LM has a significant positive effect on BP and explains $48.2 \%$ of variance in this variable. Results also show that the influencing factors studied in this research, collectively, accounted for $50.3 \%$ of variance in LM. 


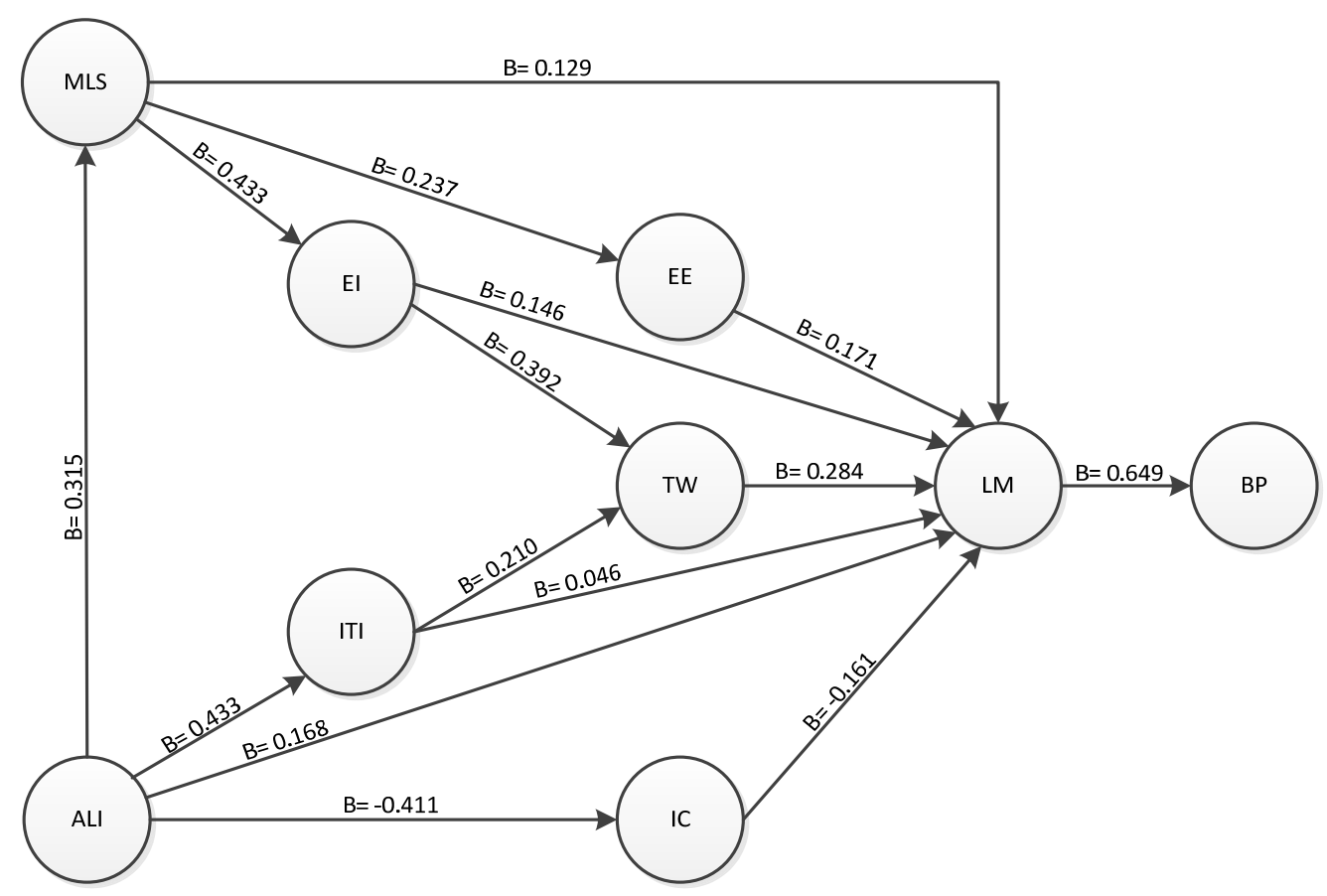

Figure 1. Results of assessment of structural path model.

Table 3. Results of structural path analysis.

\begin{tabular}{|c|c|c|c|}
\hline Path & Path Coefficient & $p$ Value & Sig Level \\
\hline $\mathrm{ALI} \rightarrow \mathrm{IC}$ & -0.411 & 0.000 & $* * *$ \\
\hline $\mathrm{ALI} \rightarrow \mathrm{IT}$ & 0.433 & 0.000 & $* * *$ \\
\hline $\mathrm{ALI} \rightarrow \mathrm{LM}$ & 0.168 & 0.024 & $*$ \\
\hline $\mathrm{ALI} \rightarrow \mathrm{MLS}$ & 0.315 & 0.000 & $* * *$ \\
\hline $\mathrm{EE} \rightarrow \mathrm{LM}$ & 0.171 & 0.029 & $*$ \\
\hline $\mathrm{EI} \rightarrow \mathrm{LM}$ & 0.146 & 0.093 & NS \\
\hline $\mathrm{EI} \rightarrow \mathrm{TW}$ & 0.392 & 0.000 & $* * *$ \\
\hline $\mathrm{IC} \rightarrow \mathrm{LM}$ & -0.161 & 0.034 & $*$ \\
\hline $\mathrm{IT} \rightarrow \mathrm{LM}$ & 0.046 & 0.522 & NS \\
\hline $\mathrm{IT} \rightarrow \mathrm{TW}$ & 0.210 & 0.010 & $* *$ \\
\hline $\mathrm{LM} \rightarrow \mathrm{BP}$ & 0.649 & 0.000 & $* * *$ \\
\hline $\mathrm{MLS} \rightarrow \mathrm{EE}$ & 0.237 & 0.007 & $* *$ \\
\hline $\mathrm{MLS} \rightarrow \mathrm{EI}$ & 0.433 & 0.000 & $* * *$ \\
\hline $\mathrm{MLS} \rightarrow \mathrm{LM}$ & 0.129 & 0.039 & $*$ \\
\hline $\mathrm{TW} \rightarrow \mathrm{LM}$ & 0.284 & 0.004 & $* *$ \\
\hline
\end{tabular}

${ }^{*} p<0.05 ;{ }^{* *} p<0.01 ;{ }^{* * *} p<0.001 ; \mathrm{NS}$, not significant.

\section{Conclusions}

Researchers often argue that practical applications are very different from theoretical studies (Williams et al. 1992). It is regularly doubted whether the actual outcome would be applicable with the theories mentioned in the reading materials (Oliver and Hunter 1998). Therefore, in this research, instead of applying the proper tools mentioned theoretically to the certain industry and discovering the lean related improvement, the researchers opted for an opposite approach, which was obtaining the analyzed results from Malaysia's present manufacturing industry and generating a guideline to improve the lean efficiency. The findings from journals reviewed and the questionnaire responses were analyzed precisely by using CB-SEM analysis tools for quantitative data collected. With the outcome obtained, a LM effectiveness guideline or model is created to improve the lean efficiency 
level for most of the manufacturing organizations in Malaysia. Not only the lean tools such as JIT, SCM, TQM and TPM are found essential in the manufacturing industry, there are also factors that contribute significantly in improving the lean efficiency outcome, such as employee empowerment, employee involvement, investment cost, team work, information technology, managerial leadership and support and awareness of latest lean information. Besides that, the precedence relationship among lean key factors were defined. In terms of theoretical implications, this research is the first to indicate the importance of precedence relationship among the lean determinants of LM implementation in Malaysia. Even if there are papers slightly related to the roles of these relationships, the outcomes do not truly explain the creation of the LM success and effectiveness model. In this study, the findings of key determinants of LM implementation in Malaysia's manufacturing industry and its precedence relationships would be the first contribution to theoretical implications.

Despite being limited to Malaysia's manufacturing industry, the overall research method such as the questionnaire and CB-SEM model represents an important contribution to the lean research world. They are a valuable starting point for LM scholars all over the world to better understand the mechanism through which firms can ensure the success of their LM practices. Also, the outcome can assist LM scholars worldwide to further explore an effective LM model in their own research settings by using the same research method as in this study. This would be a significant theoretical implication that could possibly inspire the LM effectiveness findings in many countries.

In addition, this study shows that CB-SEM are complementary analytical tools that are essential for initial development of a hypothetical lean model. CB-SEM is used to validate the model statistically. By using CB-SEM, the data collected throughout the study would be able to go through further empirical testing and strengthen the reliability of the findings. Besides, a practical research lean model is able to develop by using these analytical tools in order to provide proper guidelines for the lean industry.

Furthermore, the practical implication shown through the data analysis is that LM is not limited to one or two practices. From the statistical results shown in the CB-SEM model, the four LM practices of JIT, TQM, TPM and SCM, collectively, develop LM. Therefore, it leads to a higher level of BPI if all LM tools are being implemented. However, having even one LM practice is still useful; therefore, Malaysian manufacturers can opt for one LM tool to be implemented in the organization before going further with the other lean tools. That means it is not necessarily to start with implementing all LM practices simultaneously as lean tools can be applied one by one.

As a conclusion, this research discovered the trend of lean tradition in the manufacturing industry in Malaysia and proposed a proper guideline in order to improve the lean efficiency level in Malaysia. This study analyzed the lean trend in Malaysia's manufacturing companies in lean perspective and factors affecting lean effectiveness by which the current and future manufacturing sectors in Malaysia can benefit from the lean model created. The following contributions are made throughout the results and findings of this research:

- Developing a model on how the manufacturers in Malaysia can improve their lean manufacturing practices through lean perspective and BPI analysis.

- Determining the validity of the proposed model analyzed using PLS-SEM to assess the lean improvement results.

- Providing practical guidelines based on results obtained for Malaysia's manufacturers to create improvement to current and future Lean Manufacturing implementation in Malaysia's manufacturing companies.

Acknowledgments: We would like to thank Fundamental Research Grant Scheme (with project number FRGS 4450/N01) for all the financial support in completing the research and paper publication.

Author Contributions: Both authors contributed equally to this work.

Conflicts of Interest: The authors declare no conflicts of interest. 


\section{References}

Anand, Gurumurthy, and Rambabu Kodali. 2009. Simulation model for the design of lean manufacturing systems-A case study. International Journal of Productivity and Quality Management 4: 691-714. [CrossRef]

Anderson, James C., and David W. Gerbing. 1988. Structural equation modeling in practice: A review and recommended two-step approach. Psychological Bulletin 103: 411-23. [CrossRef]

Anvari, Alireza, Yusof Ismail, and Seyed Mohammad Hossein Hojjati. 2011. A study on total quality management and lean manufacturing: Through lean thinking approach. World Applied Sciences Journal 12: 1585-96.

Ayers, James B. 2002. A primer on supply chain management. Information Strategy 16: 6-17.

Barclay, Donald, Christopher Higgins, and Ronald Thompson. 1995. The partial least squares (PLS) approach to causal modeling: Personal computer adoption and use as an illustration. Technology Studies 2: 285-309.

Besterfield, Dale H., Carol Besterfield-Michna, Glen Besterfield, and Mary Besterfield-Sacre. 1995. Total Quality Management. New York: Prentice-Hall.

Byfuglien, Jan, Heidi Torstensen, Anne Trolie, and Norway Statistics. 2013. The improvement of HR management by using lean. Compilation of Good Practices in Statistical Offices 23: 253.

Chin, Wynne W. 1998. Issues and opinion on structural equation modeling. MIS Quarterly 22: 7-16.

Dawson, P. (1994). Quality management: beyond the Japanese model. International Journal of Quality $\mathcal{E}$ Reliability Management 11: 51-59.

Deif, Ahmed M. 2012. Dynamic analysis of a lean cell under uncertainty. International Journal of Production Research 50: 1127-39. [CrossRef]

Feld, William M. 2001. Lean manufacturing: A 'Holistic' view. In Lean Manufacturing: Tools, Techniques, and How to Use Them. Boca Raton: CRC Press, vol. 5, pp. 3-6.

Fliedner, Gene, and Karl Majeske. 2010. Sustainability: The new lean frontier. Production and Inventory Management Journal 46: 6-13.

Fornell, Claes. 1982. A Second Generation of Multivariate Analysis: Methods. New York: Praeger, vol. 1.

Fornell, Claes, and David F. Larcker. 1981. Evaluating structural equation models with unobservable variables and measurement error. Journal of Marketing Research 18: 39-50. [CrossRef]

Hair, Joseph F., William C. Black, Barry J. Babin, Rolph E. Anderson, and Ronald L. Tatham. 2006. Multivariate Data Analysis. Upper Saddle River: Pearson Prentice Hall, vol. 6.

Hair, Joseph F., Jr., G. Tomas M. Hult, Christian Ringle, and Marko Sarstedt. 2013. A Primer on Partial Least Squares Structural Equation Modeling (PLS-SEM). Thousand Oaks: Sage Publications.

Herron, Colin, and Paul M. Braiden. 2006. A methodology for developing sustainable quantifiable productivity improvement in manufacturing companies. International Journal of Production Economics 104: 143-53. [CrossRef]

Hibadullah, Siti Norhafizan, Nurul Fadly Habidin, Farah Izzaida Mohd Zamri, Nursyazwani Mohd Fuzi, and Auni Fatin Nadia Chiek Desa. 2014. Critical success factors of lean manufacturing practices for the Malaysian automotive manufacturers. International Journal of Quality and Innovation 2: 256-71. [CrossRef]

Holweg, Matthias. 2007. The genealogy of lean production. Journal of Operations Management 25: 420-37. [CrossRef]

$\mathrm{Hu}$, Li-tze, and Peter M. Bentler. 1998. Fit indices in covariance structure modeling: Sensitivity to under parameterized model misspecification. Psychological Methods 3: 424. [CrossRef]

Jamian, R., M. N. Ab Rahman, B. M. Deros, and N. Z. N. Ismail. 2012. A conceptual model towards sustainable management system based upon 5s practice for manufacturing SMEs. Asia Pacific Journal of Operations Management 1: 19-31.

Karim, Azharul, and Kazi Arif-Uz-Zaman. 2013. A methodology for effective implementation of lean strategies and its performance evaluation in manufacturing organizations. Business Process Management Journal 19: 169-96. [CrossRef]

Kilpatrick, Jerry. 2003. Lean principles. Utah Manufacturing Extension Partnership 68: 1-5.

Kumar, Sanjay, Bhim Singh, Mohammed Asim Qadri, Yv Satya Kumar, and Abid Haleem. 2013. A framework for comparative evaluation of lean performance of firms using fuzzy TOPSIS. International Journal of Productivity and Quality Management 11: 371-92. [CrossRef]

Lapinski, Anthony R., Michael J. Horman, and David R. Riley. 2006. Lean processes for sustainable project delivery. Journal of Construction Engineering and Management 132: 1083-91. [CrossRef]

Loughrin, M. 2010. The Four Elements of Lean Leadership. Springboro: Supply Chain Digest. 
Melton, Trish. 2004. To lean or not to lean? (That is the question). The Chemical Engineer 759: 34-37.

Miller, Geoff, Janice Pawloski, and Charles Robert Standrigde. 2010. A case study of lean, sustainable manufacturing. Journal of Industrial Engineering and Management 3: 11-32.

Murman, Earll, Thomas Allen, Kirkor Bozdogan, Joel Cutcher-Gershenfeld, Hugh McManus, Deborah Nightingale, Eric Rebentisch, Tom Shields, Fred Stahl, Myles Walton, and et al. 2002. Lean Enterprise Value: Insights from MIT's Lean. Cham: Springer.

Nordin, Norani, Baba Md Deros, and Dzuraidah Abd Wahab. 2010. A survey on lean manufacturing implementation in Malaysian automotive industry. International Journal of Innovation Management and Technology 1: 374-80.

Oliver, Nick, and Gillian Hunter. 1998. The financial impact of 'Japanese' manufacturing methods. Manufacturing in Transition 5: 81-91.

Petter, Stacie, Detmar Straub, and Arun Rai. 2007. Specifying formative constructs in information systems research. MIS Quarterly 31: 623-56. [CrossRef]

Poduval, Prasanth S., and V. R. Pramod. 2015. Interpretive Structural Modeling (ISM) and its application in analyzing factors inhibiting implementation of Total Productive Maintenance (TPM). International Journal of Quality E Reliability Management 32: 308-31.

Rai, Arun, Ravi Patnayakuni, and Nainika Seth. 2006. Firm performance impacts of digitally enabled supply chain integration capabilities. MIS Quarterly 30: 225-46. [CrossRef]

Shah, Rachna, and Peter T. Ward. 2003. Lean manufacturing: Context, practice bundles, and performance. Journal of Operations Management 21: 129-49. [CrossRef]

Shah, Rachna, and Peter T. Ward. 2007. Defining and developing measures of lean production. Journal of Operations Management 25: 785-805. [CrossRef]

Sharma, Ashok Kumar, and Awadhesh Bhardwaj Shudhanshu. 2012. Manufacturing performance and evolution of TPM. International Journal of Engineering Science and Technology 4: 854-66.

Shetty, Devdas, Ahad Ali, and Robert Cummings. 2010. Survey-based spreadsheet model on lean implementation. International Journal of Lean Six Sigma 1: 310-34. [CrossRef]

Singh, Ranteshwar, Ashish M. Gohil, Dhaval B. Shah, and Sanjay Desai. 2013. Total Productive Maintenance (TPM) implementation in a machine shop: A case study. Procedia Engineering 51: 592-99. [CrossRef]

Sai Hong, Tang, and Morteza Ghobakhloo. 2013. IT investments and product development effectiveness: Iranian SBs. Industrial Management \& Data Systems 113: 265-93.

Taylor, W. Andrew, and Gillian H. Wright. 2003. A longitudinal study of TQM implementation: Factors influencing success and failure. Omega 31: 97-111. [CrossRef]

United Nations Environment Programme, Division of Early Warning, and Assessment. 2011. UNEP Year Book 2011: Emerging Issues in Our Global Environment. Nairobi: UNEP/Earthprint.

Wartzman, R. 2007. Has Toyota Lost Its Way? Business Week 5: 46-50.

Williams, Karel, Colin Haslam, John Williams, Tony Cultler, Andy Adcroft, and Sukhdev Johal. 1992. Against lean production. Economy and Society 21: 321-54. [CrossRef]

Womack, James P., and Daniel T. Jones. 2010. Lean Thinking: Banish Waste and Create Wealth in Your Corporation. New York: Simon and Schuster.

Wong, Yu Cheng, and Kuan Yew Wong. 2011. Approaches and practices of lean manufacturing: The case of electrical and electronics companies. African Journal of Business Management 5: 2164-74.

(C) 2018 by the authors. Licensee MDPI, Basel, Switzerland. This article is an open access article distributed under the terms and conditions of the Creative Commons Attribution (CC BY) license (http://creativecommons.org/licenses/by/4.0/). 